\title{
Variações na morfoanatomia foliar de Aechmea lindenii (E. Morren) Baker var. lindenii (Bromeliaceae) sob distintas condições ambientais ${ }^{1}$
}

\author{
Caroline Heinig Voltolini ${ }^{2,3}$ e Marisa Santos ${ }^{2}$
}

Recebido em 14/05/2009. Aceito em 22/09/2010

\begin{abstract}
RESUMO
(Variações na morfoanatomia foliar de Aechmea lindenii (E. Morren) Baker var. lindenii (Bromeliaceae) sob distintas condições ambientais). Aechmea lindenii (E. Morren) Baker var. lindenii (Bromeliaceae-Bromelioideae) ocorre em restingas e Floresta Pluvial de Encosta Atlântica em Santa Catarina e Nordeste do Rio Grande do Sul, BR. Pode ser encontrada total ou parcialmente exposta à irradiação solar e em distintas formas de vida terrícola, rupícola e epifítica. O objetivo deste trabalho foi comparar morfoanatomicamente às características de folhas de A. lindenii var. lindenii em distintas condições ambientais. Foram coletadas, na Ilha de Santa Catarina (Florianópolis, SC), folhas de plantas terrícolas em restinga herbácea (alta irradiação solar), rupícolas de costões rochosos (alta irradiação solar), terrícolas e epifíticas de sub-bosques (baixa irradiação solar) de restinga arbórea e rupícolas de sub-bosque (baixa irradiação solar) de Floresta Pluvial de Encosta Atlântica. Foram mensurados comprimento, largura, área da lâmina e bainha foliar, densidade estomática, comprimento e largura das célulasguarda, espessura total e das estruturas constituintes na lâmina foliar. As características anatômicas qualitativas são semelhantes nas distintas condições analisadas. A baixa irradiação solar determina maior expansão da área foliar, decorrente do alongamento da lâmina. Lâmina e bainha foliares têm maior largura sob alta irradiação. A densidade estomática foi maior em folhas de plantas sob alta irradiação solar. A espessura total da lâmina foliar foi menor em plantas terrícolas sob alta irradiação, porém não mostrou diferenças estatísticas significativas entre as outras condições.
\end{abstract}

Palavras-chave: Respostas à irradiação solar, restinga, Floresta Pluvial Atlântica, formas de vida

\begin{abstract}
(Leaf morphoanatomy variation in Aechmea lindenii (E. Morren) Baker var. lindenii (Bromeliaceae) under distinct environmental conditions). Aechmea lindenii (E. Morren) Baker var. lindenii (Bromeliaceae-Bromelioideae) occurs in restingas and hillside Atlantic rain forest in Santa Catarina and northeastern Rio Grande do Sul, Brazil. It is found totally or partially exposed to solar radiation and in different life forms - terricolous, rupicolous and epiphytes. The aim of this work was to compare morphoanatomical leaf characteristics of A. lindenii var. lindenii in distinct environmental conditions. On Santa Catarina Island (Florianópolis, SC), the following were collected: leaves of terricolous plants in the herbaceous restinga (high solar radiation), rupicolous from rocky coast (high solar radiation), terricolous and understory epiphytes (low solar radiation) in the arboreal restinga and understory rupicolous (low solar radiation) from hillside Atlantic rain forest. We measured length, breadth and area of leaf blade and sheath, stomatal density, length and breadth of guard-cells; width of leaf blade and structural components. Qualitative anatomical characteristics are similar in the distinct conditions analyzed. Low solar radiation determined greater expansion of the leaf area, due to stretching of the blade. Leaf blade and sheath have greater breadth under high solar radiation. Stomatal density was greater in leaves of plants in high solar radiation. Total blade leaf width was smaller in leaves of terricolous plants under high solar radiation, nevertheless, statistically significant differences were not found among other conditions.
\end{abstract}

Key words: Responses to solar radiation, restinga, Atlantic rain forest, life forms

\footnotetext{
Parte da dissertação de Mestrado da primeira Autora

2 Universidade Federal de Santa Catarina, Departamento de Botânica, Florianópolis, SC, Brasil

3 Autora para correspondência: carolinevoltolini@gmail.com
} 


\section{Introdução}

A família Bromeliaceae está amplamente distribuída nas Américas, especialmente nas regiões tropicais e subtropicais (Judd et al. 1999, Benzing 2000). Tradicionalmente Bromeliaceae possui três subfamílias - Pitcairnioideae, Tillandsioideae e Bromelioideae (Reitz 1983), contudo estudos filogenéticos recentes indicam Pitcairnioideae como parafilética, sugerindo a inclusão de novas subfamílias (Givnish et al. 2009). Em Bromelioideae, conforme referem Smith \& Downs (1979) e Reitz (1983), as plantas são geralmente epífitas, apresentando sistema radicular reduzido, o qual serve para fixação no substrato, porém a absorção de água e nutrientes é realizada por tricomas peltados irregulares, os quais recobrem a lâmina foliar; a margem foliar é inteira ou serrilhada; as folhas formam tanques basais onde há armazenamento de água. O gênero Aechmea Ruiz \& Pavon pertence à Bromelioideae, sendo constituído por cerca de 172 espécies (Smith \& Downs 1979, Reitz 1983). No Estado de Santa Catarina ocorrem 17 espécies de Aechmea, entre elas A. lindenii (E. Morren) Baker, que possui duas variedades: makoyana e lindenii (Reitz 1983). O autor refere que A. lindenii var. lindenii, é endêmica do litoral de Santa Catarina e do Nordeste do Rio Grande do Sul (Torres), ocorrendo desde restingas até florestas de encostas. O autor ainda menciona que esta variedade pode ocorrer como epifítica, rupícola e terrícola (Reitz 1983). Lenzi et al. (2006) constataram variações morfológicas e reprodutivas entre $A$. lindenii var. lindenii presente em ambientes de restinga herbácea (alta irradiação solar), sub-bosque de restinga arbórea (baixa irradiação solar).

Diversos fatores limitantes para o estabelecimento e desenvolvimento de espécies vegetais são observados na restinga, em ambientes de dunas costeiras ocorrem fatores de estresse como borrifos marinhos, soterramento por areia, inundações, seca, alta irradiação solar, altas temperaturas, exposição ao vento, salinidade e deficiência nutricional (Hesp 1991). Respostas adaptativas, expressas em estratégias morfoanatômicas e fisiológicas, permitem a sobrevivência das plantas sob distintas condições ambientais (Lambers et al. 1998). Podem ocorrer aclimatações na estrutura de folhas maduras afetadas pelo nível de irradiação solar (quantidade e qualidade), ao qual estão expostas durante o desenvolvimento (Dickison 2000).

Atuais pesquisas envolvendo anatomia de outras espécies de Aechmea, em sua maioria abordam aspectos taxonômicos e alguns filogenéticos e ecológicos (Scarano et al. 2002, Aoyama \& Sajo 2003, Proença \& Sajo 2004, Sousa et al. 2005, Horres et al. 2007).

Este estudo abordará a anatomia de folhas de Aechmea lindenii (E. Morren) Baker var. lindenii, sob diferentes exposições à irradiação solar (alta, em restinga herbácea e baixa em restinga arbórea) e com distintas formas de vida - terrícola, rupícola e epifítica. A investigação pretende contribuir para o melhor entendimento da biologia e adaptações desta espécie relacionadas às diferentes condições de sobrevivência.

\section{Material e métodos}

Para o estudo foram utilizadas folhas totalmente expandidas de Aechmea lindenni (E. Morren) Baker var. lindenni de no mínimo 5 plantas adultas por condição analisada. Exemplares do táxon estudado nos diferentes pontos de coleta, após identificação, foram depositados no Herbário FLOR (UFSC, Florianópolis, SC) sob números: 36.272, $36.275,36.276,36.277$ e 36.871 .

As coletas do material foram realizadas na Ilha de Santa Catarina (Florianópolis, SC, Brasil), que está situada entre as latitudes $27^{\circ} 22^{\prime} 45^{\prime \prime}$ e $27^{\circ} 50^{\prime} 10^{\prime \prime}$ e longitude $48^{\circ} 21^{\prime} 37^{\prime \prime}$ e $48^{\circ} 34^{\prime} 49^{\prime \prime}$ (Fig. 1-2), possui um clima do tipo Cfa, de acordo com Köeppen, subtropical úmido, com temperatura média anual de $20^{\circ} \mathrm{C}$ (Atlas de Santa Catarina 1986). A precipitação total anual é de $1400 \mathrm{~mm}$, sem déficit hídrico (há excedente anual de 400-600 mm) e a umidade relativa anual é de 8085\% (Atlas de Santa Catarina 1986).

Para cada condição analisada (Tab. 1), foi mensurada a irradiância com quantômetro LI-COR Model LI-250 light meter utilizando-se a metodologia conforme Scarano et al. (2002). A análise do teor de matéria orgânica foi realizado, em triplicata, no Laboratório Físico Químico e Biológico da Companhia Integrada de Desenvolvimento Agrícola de Santa Catarina- CIDASC. Solos com teor de matéria orgânica até 1,5\% são classificados como nível baixo; de 1,6 a 3,0\%, nível médio; e acima de 3,0\%, nível alto (Guimarães et al. 1980).

Para avaliar a área foliar média, de cada folha, foram delineados os contornos das lâminas foliares, em papel $75 \mathrm{~g} /$ $\mathrm{m}^{2}$, com densidade constante (tamanho ofício padrão). Os moldes foram recortados e medidos em balança digital. A massa destes moldes foi relacionada à massa de área conhecida $\mathrm{em} \mathrm{cm}^{2}$ do mesmo papel, para a determinação da área foliar em $\mathrm{cm}^{2}$. Foram medidas as dimensões da lâmina e bainha foliar: comprimento ( $\mathrm{C}=$ eixo longitudinal, desde a base até o ápice) e largura ( $\mathrm{L}=$ eixo transversal, de bordo a bordo, na região média).

Os terços médios da lâmina e da bainha foliar, foram seccionados paradérmica, transversal e longitudinalmente, na porção central entre bordos. As amostras foram analisadas em microscópio Leica MPS 30 DMLS e as imagens foram capturadas com câmara digital Sony P92.

Foram feitas secções à mão-livre, nas amostras, com auxílio de lâmina de barbear, para confecção de lâminas temporárias, com água, e semipermanentes, com gelatina-glicerinada (Kaiser 1880, apud Kraus \& Arduin 1997), estas foram utilizadas para a determinação da densidade estomática e dimensões das células-guarda. A contagem do número de estômatos por área, em regiões sulcadas da lâmina foliar, foi obtida projetando as imagens, com câmara clara acoplada ao microscópio óptico CarlZeiss Jena, sobre área delimitada conhecida. Imagens das 
Tabela 1. Condições analisadas, local de coleta, coordenadas, hábitat, irradiância solar (IS) e teor de matéria orgânica das plantas de Aechmea lindenii (E. Morren) Baker var. lindenii (IS- irradiância solar $n=20$; matéria orgânica $n=3$ ).

\begin{tabular}{|c|c|c|c|c|c|}
\hline Condição & Local de coleta & Coordenadas & Hábitat & IS (mmoles $\mathrm{m}-2 \mathrm{~s}-1$ ) & Matéria orgânica (\%) \\
\hline Terrícola sob alta irradiação solar & Rio Tavares & UTM 22J 0749383 e 6938212 & Restinga & $741,82 \pm 22,95$ & $1,55 \pm 1,38$ \\
\hline Terrícola sob baixa irradiação solar & Lagoa do Peri & UTM 22J 0745642 e 6930651 & Restinga & $8,11 \pm 7,89$ & $6,82 \pm 3,24$ \\
\hline Rupícola sob alta irradiação solar & Barra da Lagoa & UTM 22J 0754918 e 6947479 & Costão Rochoso & $566,96 \pm 25,24$ & $56,87 \pm 10,95$ \\
\hline Rupícola sob baixa irradiação solar & Lagoa do Peri & UTM 22J 0744601 e 6928785 & $\begin{array}{l}\text { Floresta Pluvial de } \\
\text { Encosta Atlântica }\end{array}$ & $7,76 \pm 7,48$ & $40,18 \pm 6,00$ \\
\hline Epifítica sob baixa irradiação solar & Lagoa do Peri & UTM 22J 0745642 e 6930651 & Restinga & $9,57 \pm 7,42$ & $53,63 \pm 20,04$ \\
\hline
\end{tabular}

células-guarda projetadas foram medidas para determinar as dimensões. Pequenas amostras foram fixadas em glutaraldeído 2,5\%, em tampão fosfato de sódio $0,1 \mathrm{M}$, em pH 7,2, por três horas. Após o material foi lavado, por três vezes em tampão fosfato de sódio e mantido, por três dias, em etilenodiamina 10\% (Carlquist 1982). Após este período, o material foi lavado em água destilada e desidratado em série etílica gradual e conservado em etanol $70^{\circ} \mathrm{GL}$. Estas amostras fixadas e desidratadas foram infiltradas em historresina (hidroxietilmetacrilato, Jung's Historesin - marca Leica). Blocos de historresina, contendo o material, foram seccionados com $5 \mu \mathrm{m}$ de espessura, em micrótomo de rotação Leica -- RM 2125 RT. As secções foram distendidas sobre lâminas de vidro contendo água, em chapa aquecedora $\left(40^{\circ} \mathrm{C}\right)$. Após a secagem das lâminas, o material foi corado com azul de toluidina $0,25 \%$ aquoso (Ruzin 1999). Estas foram utilizadas para a determinação da espessura da lâmina foliar e estruturas constituintes através de imagens capturadas em microscópio óptico e as medidas realizadas com auxílio do programa computacional ANATI-QUANTI (Aguiar et al. 2007).

Para todos os estudos quantitativos foram determinados o número mínimo amostral pela equação $\mathrm{n}=\left(\mathrm{t}^{2} \cdot \mathrm{s}^{2}\right) \cdot \mathrm{d}^{-2}$, onde " $\mathrm{t}$ " é dado pela tabela de Student (considerando n-1, para significância de 0,05), "s" é o desvio padrão e "s" é igual a $\mathrm{E} / 100$.média, onde $\mathrm{E}=10$ para $10 \%$ de probabilidade, valor considerado satisfatório (Sokal \& Rohlf 1969). Foram avaliadas a normalidade dos dados com o teste Shapiro-wilk e a homogeneidade das variâncias com o teste Levene através dos programas computacionais BioEstat 5.0 (Ayres et al. 2007) e Statistica 7.0 (Statistica 2004), respectivamente. Após foram aplicadas transformações, quando necessário, e os dados obtidos para os cinco tratamentos foram comparados por análise de variância ANOVA (one-way), seguido por teste Tukey (ao nível de significância de 5\%), quando paramétricos ou por análise Kruskal-Wallis seguido de teste DUM, quando não-paramétricos, através dos programas computacionais Statistica 7.0. e BioEstat 5.0, respectivamente.

\section{Resultados e discussão}

Aechmea lindenii var. lindenii possui aspecto rosetado decorrente da filotaxia espiralada e tem bainhas foliares imbricadas (Fig. 1-6), o que favorece o acúmulo de água.
As folhas são perenes, têm forma lanceolada, sendo constituídas por lâmina, com espinhos marginais, e bainha. Os espinhos marginais são rígidos e recurvados sendo raros ou ausentes na bainha. Morfologicamente, a delimitação entre lâmina e bainha é caracterizada por tênue saliência. A face adaxial da bainha é levemente arroxeada. A filotaxia espiralada é característica da família Bromeliaceae (Benzing 1980). Algumas adaptações foliares em bromélias garantem suprimento de água e nutrientes em ambientes nos quais as raízes são prioritariamente fixadoras (epifíticas e rupícolas), em algumas espécies há presença de folhas estreitas e densamente cobertas por tricomas, os quais absorvem água e nutrientes quando a superfície está úmida enquanto que em outras espécies, bainhas amplas e imbricadas, formando um tanque onde acumulam água e detritos além dos tricomas absorventes (Benzing et al. 1976; Benzing 2000).

As lâminas foliares de A. lindenii var. lindenii mostramse mais alongadas sob baixa irradiação solar, em relação àquelas sob alta irradiação, determinando aumento na área, embora com menor largura (Tab. 2). Maior expansão da superfície de folhas de sombra, em relação às de sol, é amplamente referido na literatura (Parkhurst \& Loucks 1972, Lambers et al.1998, Cao 2000, Rôças et al. 2001), o que favorece a captação de fótons (Lee et al. 1996). A bainha foliar apresenta maior largura e maior área sob alta irradiação (Tab. 2). Plantas sob alta irradiação solar possuem folhas mais imbricadas (Fig.1-2), em decorrência da maior largura da bainha, fator este que favorece a melhor formação do tanque de reserva de água. Lenzi et al. (2006) relatam que folhas de A. lindenii var. lindenii em ambientes de restinga herbácea (totalmente expostas à irradiação solar) são mais curtas, largas e coriáceas em relação as de restinga arbórea (sombreadas), estas mais longas, estreitas e membranáceas.

As folhas de A. lindenii var. lindenii independente do grau de exposição à irradiação solar e da forma de vida apresentam característica anatômicas qualitativas semelhantes. $\mathrm{Na}$ lâmina foliar ocorrem tricomas peltados em ambas as faces (Fig.7-8) e estômatos restritos à face abaxial em regiões sulcadas (Fig. 8-9). A epiderme é uniestratificada e apresenta corpos silicosos (Fig. 10), paredes anticlinais sinuosas e membrana cuticular espessa. Em posição subepidermica, ocorre esclerênquima, hidrênquima, clorênquima, feixes vasculares e cordões de fibras extra-vasculares (Fig. 11-15). 

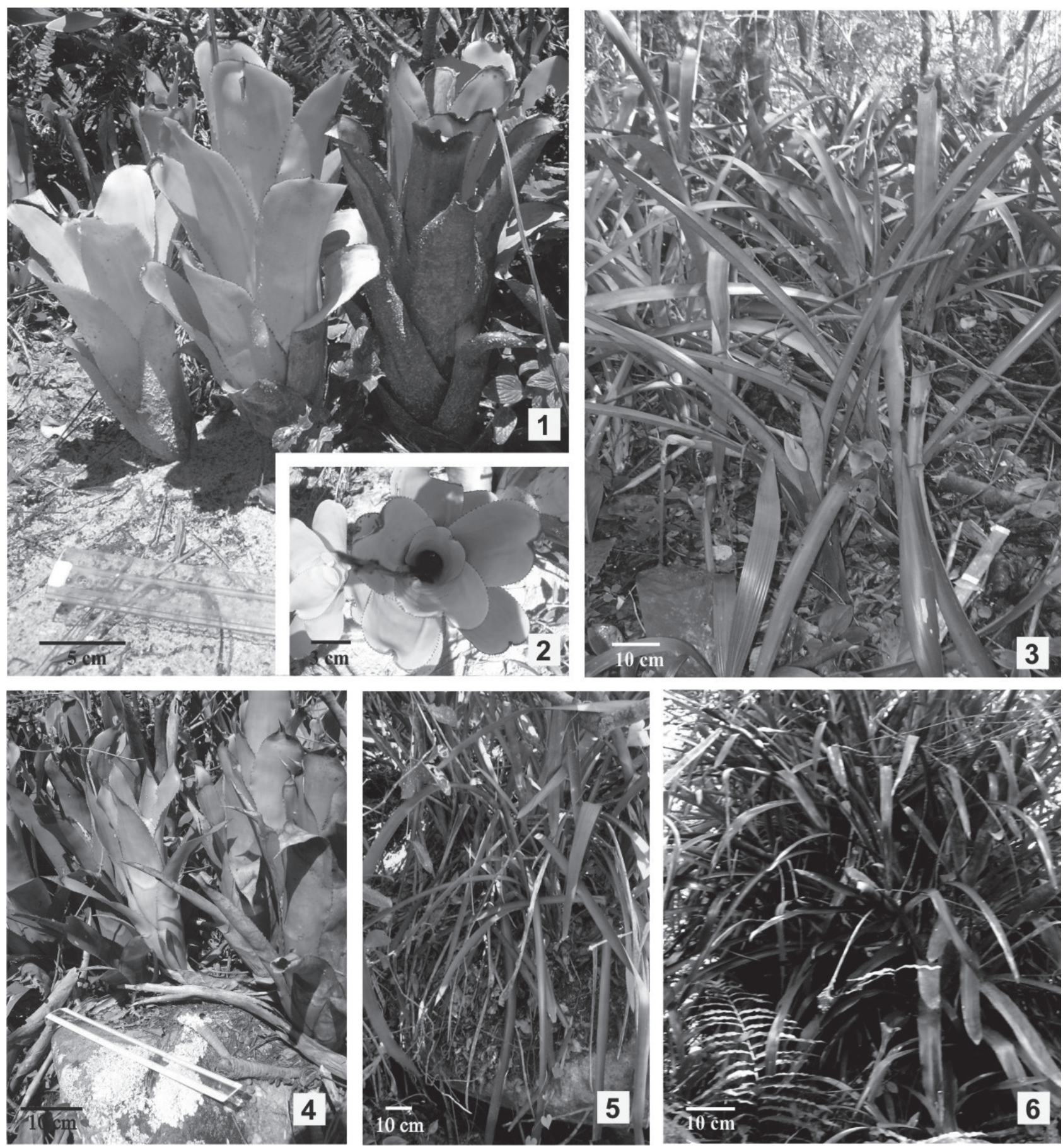

Figuras 1-6. Aspectos gerais da arquitetura foliar de Aechmea lindenii (E.Morren) Baker var. lindenii. 1-2. Terrícola sob alta irradiação solar. 3. Terrícola sob baixa irradiação solar. 4. Rupícola sob alta irradiação solar. 5. Rupícola sob baixa irradiação solar. 6. Epifítica sob baixa irradiação solar.

A disposição dos tecidos na bainha foliar de A. lindenii var. lindenii é semelhante à lâmina, com exceção da presença de aerênquima entre os feixes vasculares (Fig. 16-18), menor alongamento das células do hidrênquima e ocorrência rara de clorênquima. Diversos autores observaram em Bromeliaceae células epidérmicas com paredes sinuosas em vista frontal, epiderme uniestratificada, presença de corpos silicosos e membrana cuticular delgada (Krauss 1949, Tomlinson 1969, Aoyama \& Sajo 2003, Proença \&
Sajo 2004, Sousa et al. 2005, Proença \& Sajo 2007). Corpos silicosos têm sido relacionados à proteção da planta contra herbivoria por serem indigestos e a economia hídrica por otimizar a refração de luz reduzindo desta forma a transpiração (Krauss 1949, Yoshida et al. 1962). A presença de clorênquima, hidrênquima e cordões de fibras extravasculares é referida para a lâmina foliar em outras espécies de Aechmea estudadas (Aoyama \& Sajo 2003, Proença \& Sajo 2004, Sousa et al. 2005). 
Tabela 2. Comprimento, largura e área da lâmina e bainha foliar de Aechmea lindenii (E. Morren) Baker var. lindenii; terrícola sob alta irradiação solar (TAI), terrícola sob baixa irradiação solar (TBI), rupícola sob alta irradiação solar (RAI), rupícola sob baixa irradiação solar (RBI) e epifíticas sob baixa irradiação solar (EBI) (n=16).

\begin{tabular}{|c|c|c|c|c|c|}
\hline & TAI & TBI & RAI & RBI & EBI \\
\hline Comprimento da lâmina foliar $(\mathrm{cm})$ & $16,14 \pm 2,74^{\mathrm{d}}$ & $115,35 \pm 16,08^{\mathrm{a}}$ & $26,24 \pm 3,10^{\mathrm{C}}$ & $94,76 \pm 12,11^{b}$ & $103,73 \pm 16,46^{a, b}$ \\
\hline Largura da lâmina foliar $(\mathrm{cm})$ & $6,45 \pm 0,58^{\mathrm{a}}$ & $3,63 \pm 0,54^{\mathrm{b}, \mathrm{c}}$ & $7,00 \pm 1,00^{\mathrm{a}}$ & $3,73 \pm 0,41^{\mathrm{b}}$ & $3,28 \pm 0,47^{\mathrm{C}}$ \\
\hline Área da lâmina foliar $\left(\mathrm{cm}^{2}\right)$ & $71,75 \pm 13,35^{\mathrm{d}}$ & $304,00 \pm 46,79^{\mathrm{a}}$ & $118,88 \pm 25,04^{\mathrm{C}}$ & $266,31 \pm 62,87^{a, b}$ & $243,81 \pm 51,56^{\mathrm{b}}$ \\
\hline Comprimento da bainha foliar $(\mathrm{cm})^{*}$ & $19,09 \pm 0,94^{\mathrm{a}}$ & $11,44 \pm 1,94^{\mathrm{C}}$ & $15,06 \pm 2,97^{\mathrm{b}}$ & $13,45 \pm 2,53^{b, c}$ & $12,48 \pm 2,95^{\mathrm{b}, \mathrm{c}}$ \\
\hline Largura da bainha foliar $(\mathrm{cm})^{*}$ & $8,14 \pm 0,43^{\mathrm{a}}$ & $5,21 \pm 0,76^{\mathrm{b}}$ & $8,14 \pm 1,57^{\mathrm{a}}$ & $5,73 \pm 0,58^{\mathrm{b}}$ & $5,08 \pm 0,60^{\mathrm{b}}$ \\
\hline Área da bainha foliar $\left(\mathrm{cm}^{2}\right)^{*}$ & $113,63 \pm 9,92^{\mathrm{a}}$ & $41,88 \pm 13,47^{\mathrm{b}}$ & $95,94 \pm 33,46^{\mathrm{a}}$ & $55,25 \pm 11,38^{\mathrm{b}}$ & $44,75 \pm 13,33^{b}$ \\
\hline
\end{tabular}

Nota: Letras diferentes comparadas horizontalmente indicam diferenças estatisticamente significativas entre as médias, ao nível de $5 \%$ de probabilidade pelo teste Tuckey (paramétrico) ou DUM* (não-paramétrico).
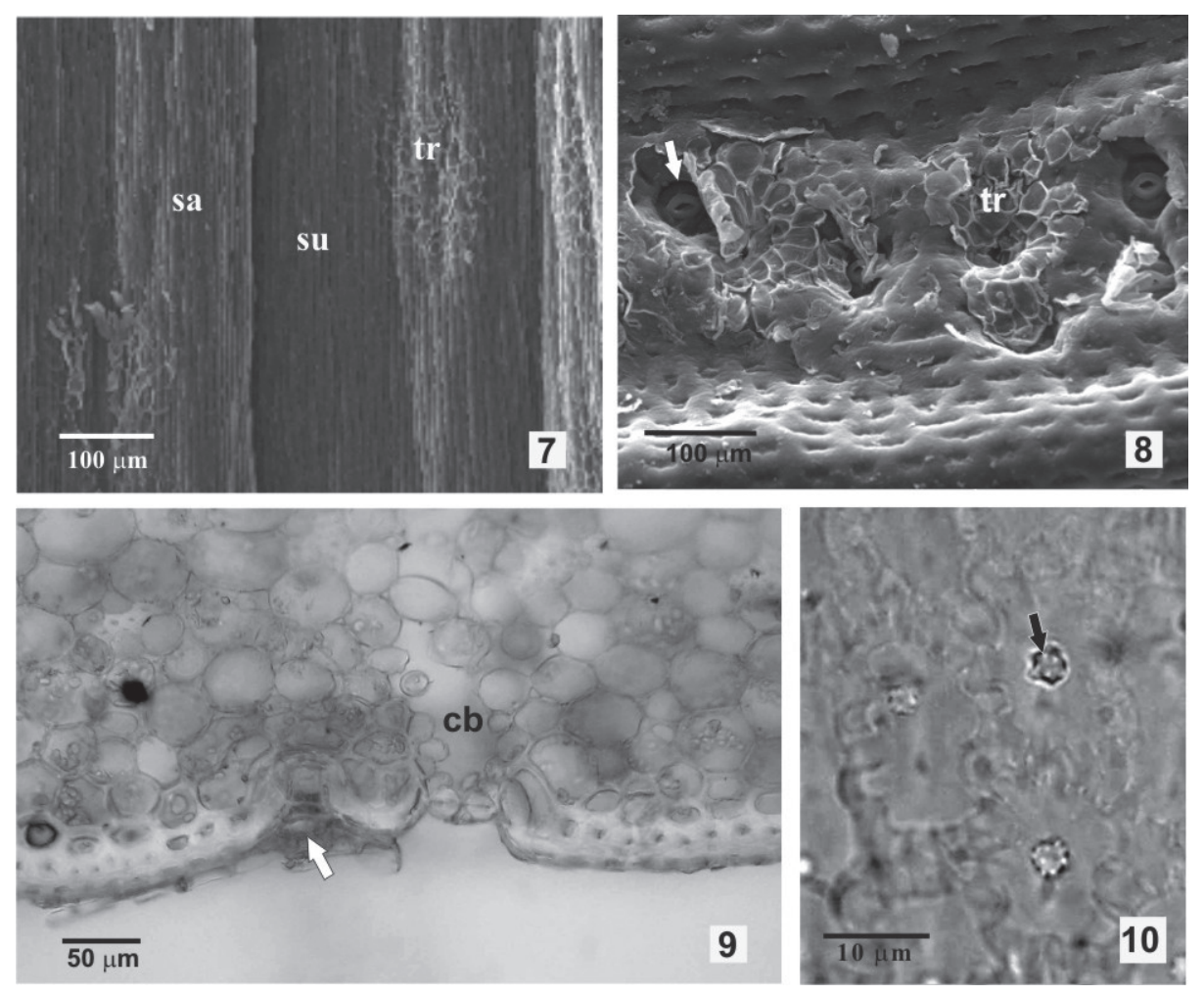

Figuras 7-10. Lâmina foliar de Aechmea lindenii (E.Morren) Baker var. lindenii. 7-8. Eletromicrografias da superfície epidérmica 7. Face adaxial. 8. Face abaxial, estômato (seta). 9. Fotomicrografia de secção transversal, tricoma (seta). 10. Fotomicrografia de vista frontal da epiderme, corpo silicoso (seta). Legenda: cb- cb-câmara subestomática, sa- saliência, su-sulco, tr-tricoma.

As espessuras das estruturas e tecidos constituintes da lâmina foliar de A. lindenii var. lindenii (membrana cuticular, célula epidérmica, esclerênquima, hidrênquima e clorênquima) mostram variações peculiares, que somadas resultam em diferenças ou semelhanças na espessura total da lâmina. Lâminas foliares menos espessas foram observadas em plantas terrícolas sob alta irradiação solar (Tab. 3). Entre as demais condições analisadas neste estudo, inclusive para plantas rupícolas sob alta irradiação solar comparadas àquelas sob baixa irradiação, não foram verificadas diferenças estatisticamente significativas (Tab. 3). A espessura do hidrênquima, tecido de reserva hídrica, atinge maior dimensão nas folhas sob baixa irradiação solar (Tab. 3). Resultados que contrariam o que usualmente é referido na literatura. Folhas de sol são mais espessas que folhas de sombra, destacando-se o maior espessamento cuticular e do parênquima paliçádico, bem como dos tecidos de reserva hídrica (Lamber et al. 1998, Dickison 2000, Taiz \& Zeiger 2004, Mantuano et al. 2006, Terashima et al. 2006). Contudo em folhas de A. bromeliifolia (Rudge) Baker (Bromeliaceae), quando em ambientes secos, o hidrênquima é mais espesso em plantas sombreadas do que naquelas totalmente expostas à irradiação solar (Scarano et al. 2002).

Com relação ao clorênquima, comparando a mesma forma de vida, plantas rupícolas apresentam maior espessura quando sob alta irradiação, correspondendo ao usualmente referido na literatura, entretanto nas terrícolas ocorre o contrário (Tab. 3). Lee et al. (1989) 


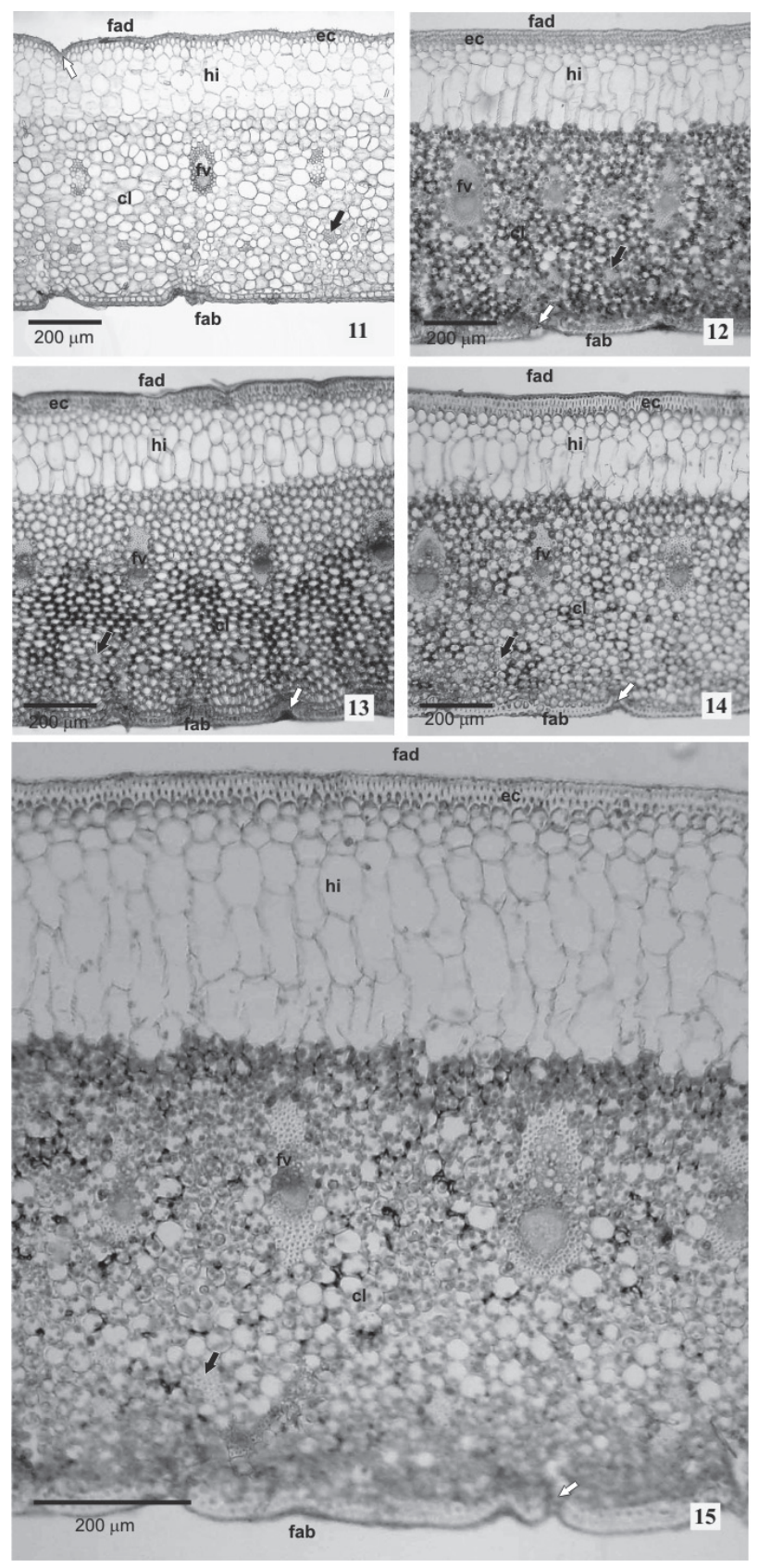

Figuras 11-15. Fotomicrografias de secções transversais da lâmina foliar Aechmea lindenii (E.Morren) Baker var. lindenii. 11. Terrícola sob alta irradiação solar. 12. Terrícola sob baixa irradiação solar. 13. Rupícola sob alta irradiação solar. 14. Rupícola sob baixa irradiação solar. 15. Epifítica sob baixa irradiação solar. Legenda: cl-clorênquima; ec-esclerênquima; fab-face abaxial; fad- face adaxial; fv- feixe vascular; hi-hidrênquima. Setas pretas- cordões de fibras extra-vasculares. Setas brancas- sulcos.

ressaltam que folhas mais expostas à irradiação tendem a ampliar os tecidos clorofilados. Scarano et al. (2002) comparando plantas de A. bromeliifolia desenvolvidas em ambiente seco e sujeito ao alagamento observaram que a espessura do clorênquima nas folhas reflete interações que não estão diretamente relacionadas com distintos níveis de exposição solar. Em ambiente seco, as folhas de plantas sombreadas apresentavam maior espessura do clorênquima em relação àquelas sob alta irradiação solar, enquanto que em ambientes sujeitos ao alagamento foi observado o oposto, folhas sob alta irradiação mostraram maior espessura deste tecido em relação às sombreadas (Scarano et al. 2002)

A maior espessura da membrana cuticular e das células epidérmicas ocorre sob alta irradiação, em ambas as faces da folha, nas terrícolas (Tab. 3). Em rupícolas, na face adaxial, apenas as células epidérmicas mostram-se mais espessas e, na face abaxial, apenas a membrana cuticular (Tab. 3). Comparando as espessuras destas estruturas das epífitas em relação às demais condições (Tab. 3), constata-se maior similaridade às plantas sob baixa irradiação, embora, na face adaxial, a espessura da membrana cuticular não é distinta das rupícolas sob alta irradiação e a espessura das células epidérmicas distingue-se também das rupícolas sob baixa irradiação. Tais fatos apontam para alguma interação entre a forma de vida, epifítica ou rupícola, e a intensidade de irradiação. Diversos autores, entre eles Napp-Zinn (1984) e Fahn \& Cutler (1992), mencionam que folhas de sol mostram maior espessura de membrana cuticular. Mantuano et al. (2006) verificou células epidérmicas adaxiais mais espessas em folhas de plantas de Erythroxylum ovalifolium Peyr (dicotiledônea-Erythroxilaceae) mais expostas à irradiação solar quando comparadas às daquelas sombreadas. Tanto a espessura da membrana cuticular da face abaxial, devido à posição mais ereta da folha, quanto das células epidérmicas adaxiais, podem ter uma função de proteção em condições de alta irradiação solar. Em ambientes de alta irradiação solar estratégias estruturais como diminuição dos ângulos foliares e o auto-sombreamento auxiliam na fotoproteção minimizando os danos potenciais por fotoinibição (Pearcy et al. 2005).

Com relação à espessura do esclerênquima em folhas de A. lindenii var. lindenii, há diferenças entre os tratamentos, em ambas faces, entretanto, é mais marcante a maior espessura deste tecido subepidérmico na face abaxial das rupícolas sob alta irradiação (Tab. 3). Os tecidos subepidérmicos esclerenquimáticos, além do importante papel na sustentação das folhas (Krauss 1949), também podem contribuir para o bloqueio do excesso de irradiação, amenizando o excesso de luz e calor. Plantas rupícolas sob alta irradiação solar recebem ventos fortes diretos provenientes do mar, enquanto que as terrícolas sob alta irradiação são protegidas pelas dunas frontais, que servem como barreiras aos ventos. Nas plantas sob baixa irradiação, a força do vento é amenizada pela proteção da vegetação no entorno.

A densidade estomática é maior nas folhas mais expostas à irradiação (Tab. 3). A densidade de tricomas reduz com a irradiação (Tab. 3), auxiliando na formação do microclima na região dos estômatos. As células-guarda expandem-se mais longitudinalmente nas folhas sob baixa irradiação, em relação àquelas sob alta irradiação, se considerada a mesma forma de vida (Tab. 3). O comprimento das células- 

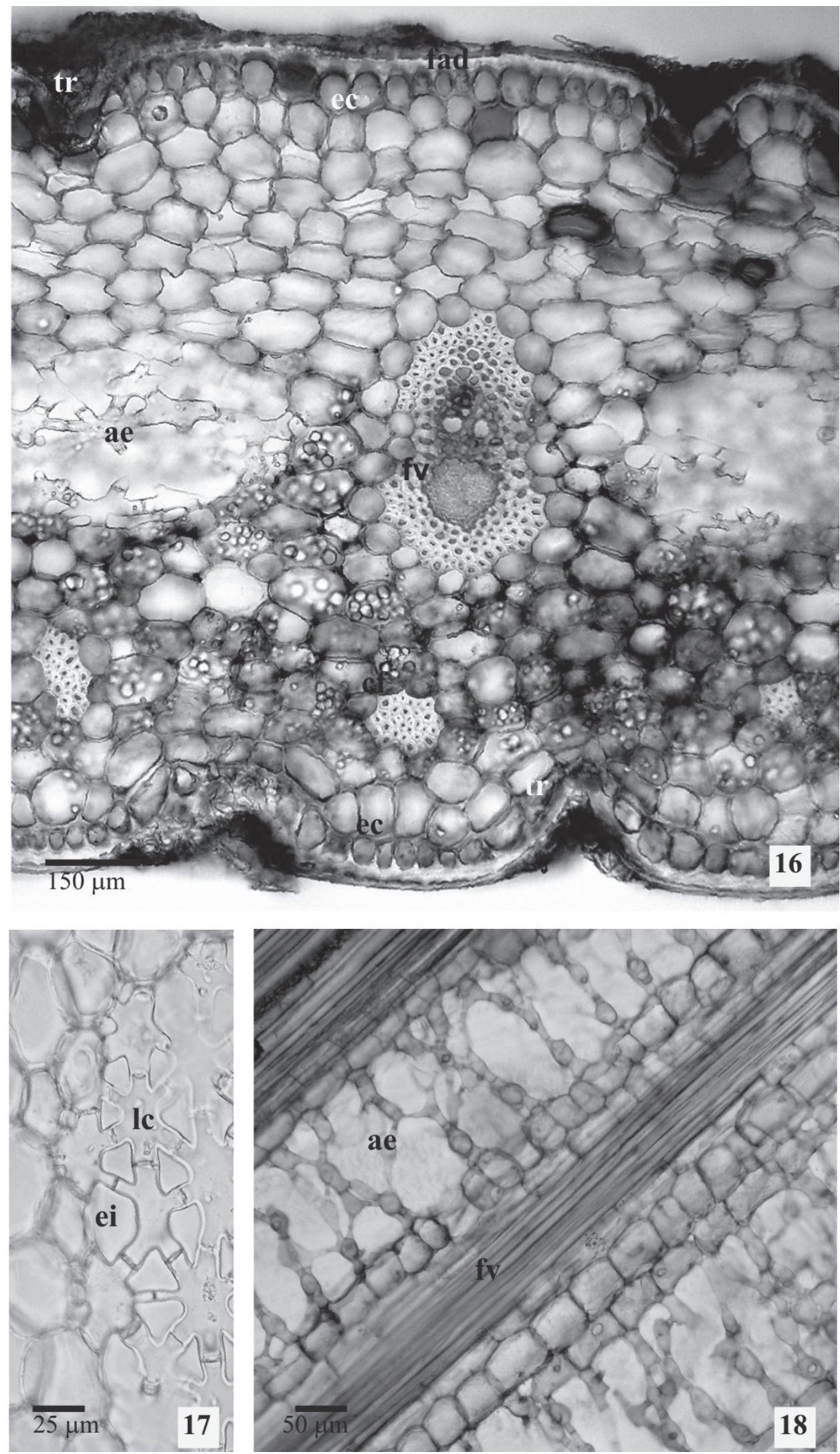

Figuras 16-18. Fotomicrografias da bainha foliar de Aechmea lindenii (E.Morren) Baker var. lindenii. 16. Secção transversal, vista geral. 17. Detalhe do aerênquima. 18. Secção longitudinal na região do aerênquima e feixes vasculares. Legenda: ae- aerênquima; cf- cordão de fibras extra-vascular; cl- clorênquima; ec-esclerênquima; ei- espaço intercelular; fad- face adaxial; fv- feixe vascular; hi- hidrênquima; lc- lúmen celular; tr-tricoma. 
Tabela 3. Dados quantitativos da lâmina foliar de Aechmea lindenii (E. Morren) Baker var. lindenii. Espessuras da lâmina foliar e tecidos constituintes (n=45) e densidade estomática de tricomas, comprimento e largura da célula-guarda $(\mathrm{n}=30)$; terrícola sob alta irradiação solar (TAI), terrícola sob baixa irradiação solar (TBI), rupícola sob alta irradiação solar (RAI), rupícola sob baixa irradiação solar (RBI) e epifíticas sob baixa irradiação solar (EBI).

\begin{tabular}{|c|c|c|c|c|c|}
\hline & TAI & TBI & RAI & RBI & EBI \\
\hline Espessura total $(\mathrm{mm})^{*}$ & $891,53 \pm 82,98^{b}$ & $1054,62 \pm 146,77^{\mathrm{a}}$ & $1096,37 \pm 170,74^{\mathrm{a}}$ & $1031,48 \pm 134,93^{\mathrm{a}}$ & $1005,46 \pm 152,57^{\mathrm{a}}$ \\
\hline $\begin{array}{l}\text { Membrana cuticular na } \\
\text { face adaxial }(\mathrm{mm})\end{array}$ & $3,81 \pm 1,07^{\mathrm{a}}$ & $3,19 \pm 0,98^{b}$ & $3,33 \pm 0,93^{\mathrm{a}, \mathrm{b}}$ & $3,00 \pm 0,82^{b}$ & $2,93 \pm 0,90^{b}$ \\
\hline $\begin{array}{l}\text { Célula epidérmica na } \\
\text { face adaxial }(\mathrm{mm})\end{array}$ & $13,59 \pm 2,61^{\mathrm{a}}$ & $8,11 \pm 1,76^{\mathrm{d}}$ & $10,97 \pm 2,45^{\mathrm{b}}$ & $9,63 \pm 2,28^{\mathrm{C}}$ & $8,18 \pm 1,91^{\mathrm{d}}$ \\
\hline $\begin{array}{l}\text { Esclerênquima na face } \\
\text { adaxial }(\mathrm{mm})^{*}\end{array}$ & $27,02 \pm 5,87^{b}$ & $29,91 \pm 9,20^{\mathrm{a}, \mathrm{b}}$ & $34,46 \pm 8,66^{\mathrm{a}}$ & $29,01 \pm 9,36^{\mathrm{a}, \mathrm{b}}$ & $26,01 \pm 12,17^{b}$ \\
\hline Hidrênquima $(\mathrm{mm})^{*}$ & $294,12 \pm 85,56^{\mathrm{b}}$ & $412,38 \pm 141,82^{\mathrm{a}}$ & $306,08 \pm 141,56^{\mathrm{b}}$ & $383,71 \pm 136,63^{\mathrm{a}}$ & $377,60 \pm 92,69^{\mathrm{a}}$ \\
\hline Clorênquima $(\mathrm{mm})^{*}$ & $522,44 \pm 85,29^{\mathrm{C}}$ & $575,48 \pm 61,11^{\mathrm{b}}$ & $707,86 \pm 60,18^{\mathrm{a}}$ & $578,64 \pm 54,28^{b}$ & $562,80 \pm 85,06^{\mathrm{b}, \mathrm{c}}$ \\
\hline $\begin{array}{l}\text { Membrana cuticular na } \\
\text { face abaxial }(\mathrm{mm})^{*}\end{array}$ & $3,24 \pm 0,88^{\mathrm{a}}$ & $2,23 \pm 0,81^{b}$ & $3,06 \pm 0,75^{\mathrm{a}}$ & $2,44 \pm 0,93^{b}$ & $2,12 \pm 0,59^{\mathrm{b}}$ \\
\hline $\begin{array}{l}\text { Célula epidérmica na } \\
\text { face abaxial }(\mathrm{mm})\end{array}$ & $8,93 \pm 2,17^{\mathrm{a}}$ & $6,25 \pm 1,45^{\mathrm{d}}$ & $8,58 \pm 1,64^{\mathrm{a}, \mathrm{b}}$ & $7,72 \pm 1,92^{b, c}$ & $6,96 \pm 1,87^{\mathrm{c}, \mathrm{d}}$ \\
\hline $\begin{array}{l}\text { Esclerênquima na face } \\
\text { abaxial }(\mathrm{mm})\end{array}$ & $18,36 \pm 5,15^{\mathrm{b}}$ & $16,93 \pm 6,81^{b}$ & $22,04 \pm 4,75^{\mathrm{a}}$ & $17,34 \pm 5,24^{b}$ & $18,86 \pm 5,51^{b}$ \\
\hline $\begin{array}{l}\text { Densidade estomática } \\
\left(\text { est } / \mathrm{mm}^{2}\right)^{*}\end{array}$ & $113,11 \pm 23,24^{\mathrm{a}}$ & $65,78 \pm 15,15^{\mathrm{b}}$ & $118,44 \pm 18,94^{\mathrm{a}}$ & $57,33 \pm 19,59^{\mathrm{b}}$ & $54,00 \pm 16,01^{\mathrm{b}}$ \\
\hline $\begin{array}{l}\text { Densidade de tricomas } \\
\left(\text { trico/mm }{ }^{2}\right)^{*}\end{array}$ & $56,22 \pm 12,67^{\mathrm{a}, \mathrm{b}}$ & $46,00 \pm 12,14^{\mathrm{c}, \mathrm{d}}$ & $64,22 \pm 10,76^{\mathrm{a}}$ & $50,89 \pm 9,73^{b, c}$ & $40,00 \pm 8,79^{d}$ \\
\hline $\begin{array}{l}\text { Comprimento das } \\
\text { células-guarda }(\mathrm{mm})^{*}\end{array}$ & $26,45 \pm 3,65^{b, c}$ & $29,57 \pm 3,90^{\mathrm{a}}$ & $23,97 \pm 3,14^{\mathrm{c}}$ & $27,91 \pm 3,09^{\mathrm{a}, \mathrm{b}}$ & $28,08 \pm 3,32^{\mathrm{a}, \mathrm{b}}$ \\
\hline $\begin{array}{l}\text { Largura das células- } \\
\text { guarda }(\mathrm{mm})\end{array}$ & $10,13 \pm 1,61^{\mathrm{a}}$ & $9,96 \pm 1,38^{\mathrm{a}}$ & $10,38 \pm 2,15^{\mathrm{a}}$ & $10,13 \pm 1,44^{\mathrm{a}}$ & $10,26 \pm 1,64^{\mathrm{a}}$ \\
\hline
\end{tabular}

Nota: Considerado lume+parede celular. Letras diferentes comparadas horizontalmente indicam diferenças estatisticamente significativas entre as médias, ao nível de $5 \%$ de probabilidade pelo teste Tuckey (paramétrico) ou $\mathrm{DUM}^{*}$ (não-paramétrico).

guarda em lâminas foliares de plantas epifíticas, sob baixa irradiação, só diferiu das rupícolas sob alta irradiação. As plantas epifíticas em muitas das características analisadas mostram um padrão intermediário entre características de plantas sob alta e baixa irradiação solar. De acordo com Abrans et al. (1992), a menor expansão das células-guarda pode minimizar a perda de água em situações de maior irradiação solar no ambiente. Em A. lindenii var. lindenii, o comprimento da célula-guarda deve estar relacionado com as características intrínsecas das folhas de monocotiledôneas, uma vez que os estômatos orientam-se longitudinalmente e há tendência a maior desenvolvimento sentido base-ápiceDe modo geral a influência das distintas formas de vida não se mostrou tão evidente nas características morfoanatômicas de $A$. lindenii var. lindenii quanto o nível de irradiação solar.

\section{Agradecimentos}

À Coordenação de Auxílio à Pesquisa de Ensino Superior (CAPES) pela bolsa de mestrado concedida à primeira autora. Ao Conselho Nacional de Desenvolvimento Científico e Tecnológico (CNPq) pela bolsa de produtividade em pesquisa à segunda autora (proc. 481623/2007-8) e auxílio financeiro (proc. 303351/2008-0).

\section{Referências Bibliográficas}

Abrans, M.C.; Kloeppel, B.D. \& Kubiske, M.E. 1992. Ecophysiological and morphological responses to shade and drought in two contrasting ecotypes of Prunus setorina. Tree Physiology 10: 343-355.

Aguiar, T.V.; Sant'anna-Santos, B.F.; Azevedo, A.A. \& Ferreira, R.S. 2007. ANATI QUANTI: Software de análises quantitativas para estudos em anatomia vegetal. Planta Daninha 25: 649-659.

Aoyama, E.M \& Sajo, M.G. 2003. Estrutura foliar de Aechmea Ruiz \& Pav. subgênero Lamprococcus (Beer) Baker e espécies relacionadas (Bromeliaceae). Revista Brasileira de Botânica 26: 461-473.

Atlas de Santa Catarina. 1986. Gabinete de Planejamento e Coordenação Geral. Subchefia de Estatística, Geografia e Informática. Rio de Janeiro, Aerofoto Cruzeiro.

Ayres, M.; Ayres, Júnior M.; Ayres D.L. \& Santos, A.S. 2007. BioEstat 5.0: Aplicações estatísticas nas áreas das ciências biológicas e médicas. Belém, Sociedade Civil Mamiraúa/CNPq.

Benzing, D.H. 1980. The Biology of the Bromeliads. Califórnia, Mad River Press.

Benzing, D.H. 2000. Bromeliaceae: Profile of an Adaptative Radiation. USA, Cambridge University Press.

Benzing, D.H.; Henderson, K.; Kessel, B. \& Sulak, J. 1976. The absortive capacities of bromeliad trichomes. American Journal of Botany 63: 1009-1014.

Cao, K.F. 2000. Leaf anatomy and chlorophyll content of 12 woody species in contrasting light conditions in a Bornean heath forest. Canadian Journal of Botany 78: 1245-1253.

Carlquist, S. 1982. The use of ethylenediamine in softening hard plant structures for paraffin sectioning. Stain Technology 57: 311-317.

Dickison, W.C. 2000. Integrative Plant Anatomy. Califórnia, Academic Press. 
Fahn, A. \& Cutler, D.F. 1992. Xerophytes. Berlin, Gebrüder Borntraeger Givnish, T.J.; Millan K.C.; Berry, P.E. \& Sytsma, K.J. 2007. Phylogeny, adaptive radiation, and historical biogeography of Bromeliaceae inferred from $n d h F$ sequence data. Aliso 23: 3-26.

Guimarães, P.T.G.; Ferreira, J.G.; Carvalho, J.G \& Lopes, A.S. 1980. Adubação de pastagens. Informe Agropecuário 70: 34-52.

Hesp, A.P. 1991. Ecological processes and plant adaptions on coastal dunes. Journal of Arid Enviromments 21: 165-191.

Horres, R.; Schulte, K.; Weising, K. \& Zizka, G. 2007. Systematics of Bromelioideae (Bromeliaceae) evidence from molecular and anatomical studies. Aliso 23: 27-43.

Judd, W.S.; Campbell, C.S.; Kellogg, E.A. \& Stevens, P.F. 1999. Plant Systematics: a phylogenetic approach. USA, Sinauer Associates.

Kraus, J.E \& Arduin, M. 1997. Manual Básico de Métodos em Morfologia Vegetal. Seropédica, Editora Universidade Rural.

Krauss, B.H. 1949. Anatomy of the vegetative organs of the pineapple, Ananas comosus (L) Merr. (continued) II. The leaf. Botanical Gazette 110: 303-404.

Lambers, H.; Stuart, F. \& Pons, T.L. 1998. Plant Physiological Ecology. New York, Springers-Verlag.

Lee, D.W.; Baskaran, K. Mansor, M.; Mohamad, H. \& Yap, S. K. 1996. Irradiance and spectral quality effect Asian tropical rain forest tree seedling development. Ecology 77: 568-580.

Lee, H.S.J.; Lüttge, U.; Medina, E.; Smith, J.A.C.; Cram, W.J.; Diaz, M.; Griffiths, H.; Popp, M.; Schäfer, C.; Stimmel, K-H. \&, Thonke, B. 1989. Ecophysiology of xerophytic and halophytic vegetation of a coastal alluvial plain in northern Venezuela III - Bromelia humilis Jacq. a terrestrial CAM bromeliad. New Phytologist 111: 253-271.

Lenzi, M.; Matos J.M. \& Orth, A.I. 2006. Variação morfológica e reprodutiva de Aechmea lindenii (E. Morren) Baker var. lindenii (Bromeliaceae). Acta Botanica Brasilica 20: 487-500.

Mantuano, D.G.; Barros, C.F. \& Scarano, F.R. 2006. Leaf anatomy variation within and between three "restinga" populations of Erythroxylum ovalifolium Peyr. (Erythroxylaceae) in Southeast Brazil. Revista Brasileira de Botânica 29: 209-215

Napp-Zinn, K. 1984. Handbuch der Pflanzenanatomie. VIII Anatomie des Blattes, 2. Blattanatomie der Angiospermen, B. Experimentelle und ökologishe Anatomie des Angiospermenblattes. Berlin, Gbdr. Borntraeger.

Parkhurst, D.F. \& Loucks, O.L. 1972. Optimal leaf size in relation to environment. Journal of Ecology 60: 505-537.
Pearcy, R.W.; Muraoka, H. \& Valladares, F. 2005. Crown architecture in sun and shade environments: assessing function and trade-offs with a three-dimensional simulation mode. New Phytologist 166: 791-800.

Proença, S.L. \& Sajo, M.G. 2004. Estrutura foliar de espécies de Aechmea Ruiz \& Pav. (Bromeliaceae) do Estado de São Paulo, Brasil. Acta Botanica Brasilica 18: 319-331.

Proença, S.L. \& Sajo, M.G. 2007. Anatomia foliar de bromélias ocorrentes em áreas de cerrado do Estado de São Paulo, SP. Acta Botanica Brasilica 21: 657-673.

Reitz, R. 1983. Bromeliáceas e a Malária-Bromélia Endêmica. In: Flora Ilustrada Catarinense. Parte I. Fascículo Bromélia.

Rôças, G.; Scarano, F.R. \& Barros, C.F. 2001. Leaf anatomical variation in Alchornea triplinervia (Spreng) Müll. Arg. (Euphorbiaceae) under distinct light and soil water regimes. Botanical Journal of the Linnean Society 136: 231-238.

Ruzin, S.E. 1999. Plant Microtechnique and Microscopy. New York, Oxford University Press.

Scarano, F.R.; Duarte, H.M.; Rôças, G.; Barreto, S.M.B.; Amado, E.F.; Reinert, F.; Wendt, T.; Mantovani, A.; Lima H.R.P. \& Barros, C.F. 2002. Acclimation or stress symptom? An integrated study of intraspecific variation in the clonal plant Aechmea bromeliifolia, a widespread CAM tankbromeliad. Botanical Journal of the Linnean Society 140: 391-401.

Smith, L.B. \& Downs, R.J. 1979. Bromelioideae (Bromeliaceae). Flora Neotropica Monograph 14: 1493-2142.

Sokal, R.R. \& Rohlf, F.J. 1969. Biometry. San Francisco, Freeman and Company.

Sousa, G.M.; Estelita, M.E.M. \& Wanderley, M.G.L. 2005. Anatomia foliar de espécies brasileiras de Aechmea subg. Chevaliera (Gaudich. ex Beer) Baker, Bromelioideae-Bromelioideae. Revista Brasileira Botânica 28: 603-613.

Statistica. 2004. StatSoft, Inc. (data analysis software system), version 7.

Taiz, L. \& Zeiger, E. 2004. Fisiologia Vegetal. 3a ed. Porto Alegre, Artmed Editora.

Terashima, I; Miyazawa, S-I \& Handa, Y.T. 2006. Why are sun leaves thicker than shade leaves? Consideration based on analyses of $\mathrm{CO}_{2}$ diffusion in the leaf. Journal of Plant Research 114: 93-105.

Tomlinson, P.B. 1969. Anatomy of the monocotyledons: III Commmelinales-Zingiberales. Oxford, Oxford University Press.

Yoshida, S.; Ohnishi, Y. \& Kitagishi, K. 1962. Histochemistry of silicon in rice plant. III. The presence of cuticle-silica double layer in the epidermal tissue. Soil Science And Plant Nutricion 8: 1-5. 